\title{
REVIEW
}

\section{Accelerating drug discovery for Alzheimer's disease: best practices for preclinical animal studies}

Diana W Shineman*1, Guriqbal S Basi², Jennifer L Bizon³, Carol A Colton ${ }^{4}$, Barry D Greenberg ${ }^{5}$, Beth A Hollister ${ }^{6}$, John Lincecum7, Gabrielle G Leblanc ${ }^{8}$, Linda (Bobbi) H Lee ${ }^{1,9}$, Feng Luo ${ }^{10}$, Dave Morgan"1, Iva Morse ${ }^{12}$, Lorenzo M Refolo ${ }^{13}$, David R Riddell14, Kimberly Scearce-Levie ${ }^{15}$, Patrick Sweeney ${ }^{16}$, Juha Yrjänheikki16 and Howard M Fillit

\begin{abstract}
Animal models have contributed significantly to our understanding of the underlying biological mechanisms of Alzheimer's disease (AD). As a result, over 300 interventions have been investigated and reported to mitigate pathological phenotypes or improve behavior in AD animal models or both. To date, however, very few of these findings have resulted in target validation in humans or successful translation to disease-modifying therapies. Challenges in translating preclinical studies to clinical trials include the inability of animal models to recapitulate the human disease, variations in breeding and colony maintenance, lack of standards in design, conduct and analysis of animal trials, and publication bias due to under-reporting of negative results in the scientific literature. The quality of animal model research on novel therapeutics can be improved by bringing the rigor of human clinical trials to animal studies. Research communities in several disease areas have developed recommendations for the conduct and reporting of preclinical studies in order to increase their validity, reproducibility, and predictive value. To address these issues in the AD community, the Alzheimer's Drug Discovery Foundation partnered with Charles River Discovery Services (Morrisville, NC, USA) and Cerebricon Ltd. (Kuopio, Finland) to convene an expert advisory panel of academic, industry, and government scientists to make recommendations on best practices for animal studies testing investigational AD therapies. The panel produced recommendations regarding the measurement, analysis, and reporting of relevant AD targets, the choice of animal model, quality control measures for breeding and colony maintenance, and preclinical animal study design. Major considerations to incorporate into preclinical study design include a priori hypotheses, pharmacokinetics-pharmacodynamics studies prior to proof-of-concept testing, biomarker measurements, sample size determination, and power analysis. The panel also recommended distinguishing between pilot 'exploratory' animal studies and more extensive 'therapeutic' studies to guide interpretation. Finally, the panel proposed infrastructure and resource development, such as the establishment of a public data repository in which both positive animal studies and negative ones could be reported. By promoting best practices, these recommendations can improve the methodological quality and predictive value of AD animal studies and make the translation to human clinical trials more efficient and reliable.
\end{abstract}

\section{Animal models of Alzheimer's disease: modeling targets, not disease}

Animal models of Alzheimer's disease (AD) pathogenesis range from Caenorhabditis elegans to aged non-human

*Correspondence: dshineman@alzdiscovery.org

'Alzheimer's Drug Discovery Foundation, 57 West 57 Street, Suite 904, New York, NY 10019, USA

Full list of author information is available at the end of the article primates, but by far the most widely used are rodent models. Most animal models used for drug discovery overexpress proteins with familial AD mutations (Table 1). While these models develop certain characteristics of AD-like pathology, they do not recapitulate the entirety of the human disease. Furthermore, it is unclear to what extent the pathogenic pathways in rodents mirror those in human AD. Other challenges in translation include mouse/human species differences (for example, differences in cerebrovascular anatomy, neuronal network complexity, connectivity and disease susceptibility, white/ 


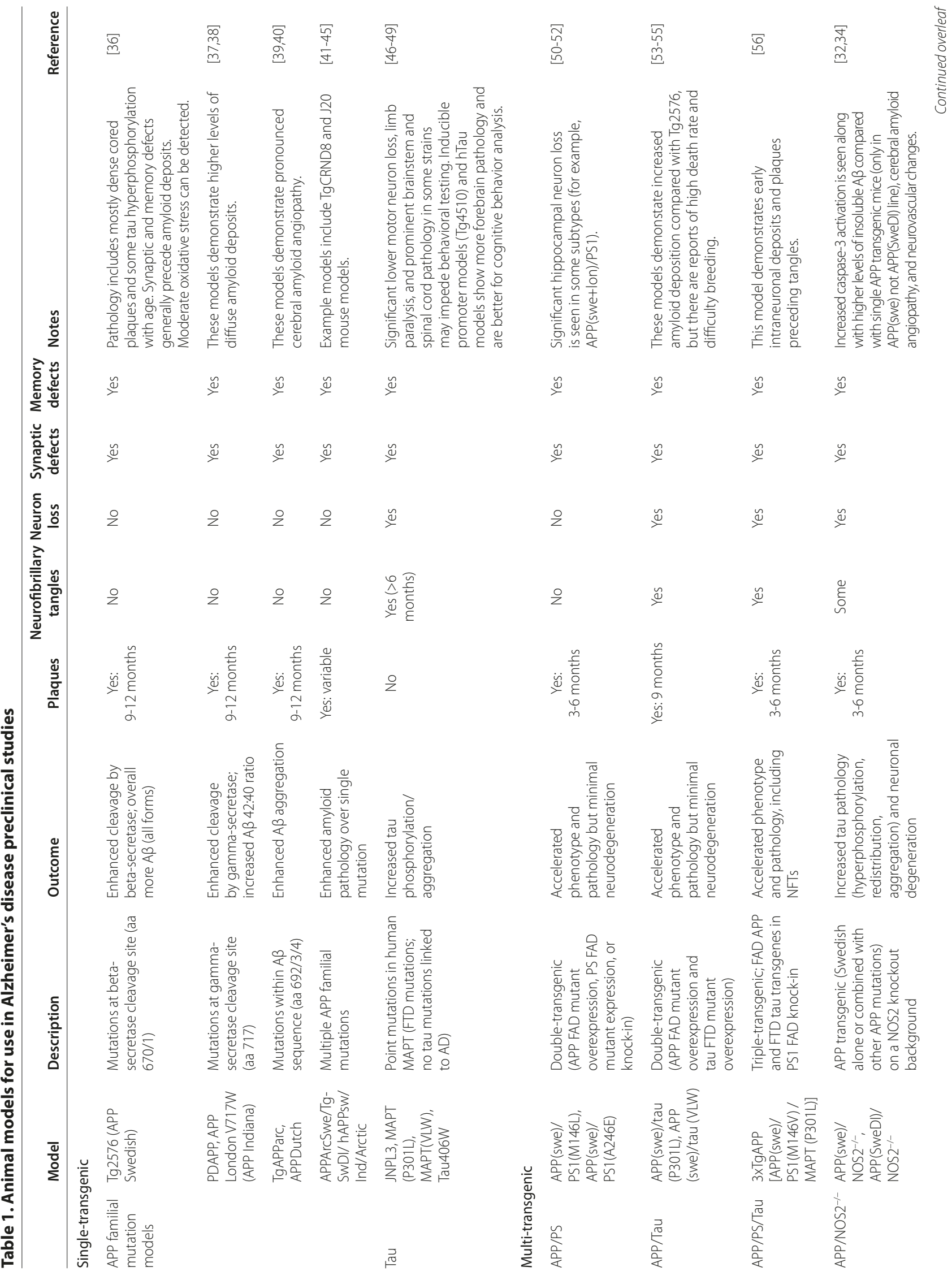




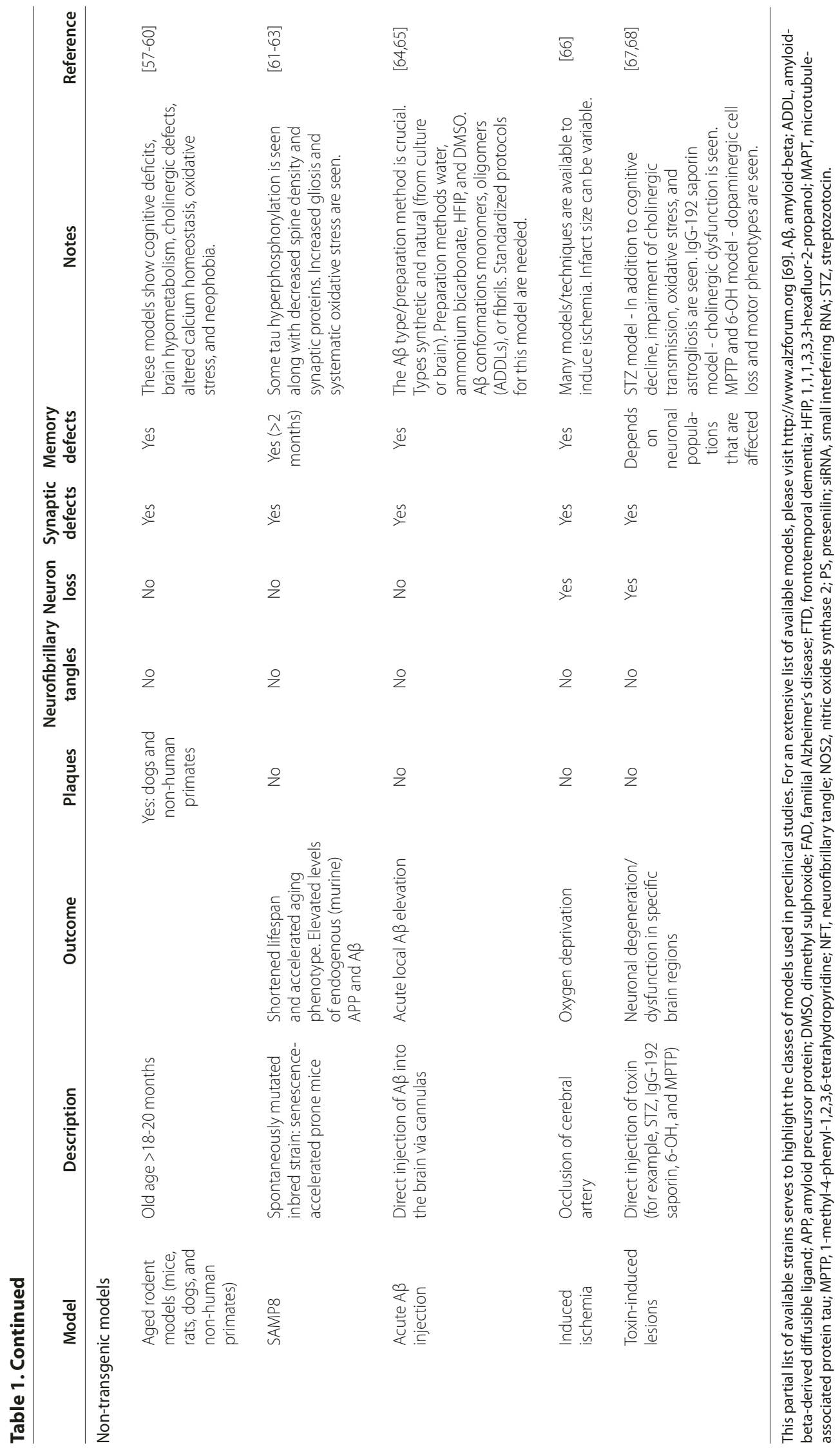


gray matter ratios, cellular redox conditions, and dynamics of drug/target interactions [1]). Nonetheless, rodent models offer a means for testing pharmacodynamic properties of candidate molecules on drug targets that may be involved in AD pathogenesis.

This target-driven approach in animal models has already translated to therapeutic studies in humans. In the amyloid-beta $(A \beta)$ immunotherapy trial of bapineuzumab, for example, the immunotherapy cleared plaques in both mice and humans [2,3]. Gamma-secretase inhibitors developed at Eli Lilly and Company (Indianapolis, IN, USA) and Bristol-Myers Squibb Company (Princeton, NJ, USA) (semagacestat and BMS-708163, respectively) showed good target-focused preclinical animal data, reducing $A \beta$ levels in mice and in the spinal fluid of human patients in a phase 2 study $[4,5]$. Demonstration of positive effects on cognitive outcomes from treatment with bapineuzumab of patients with $\mathrm{AD}$ is in the final stages of clinical testing. The phase 3 clinical trial of semagacestat was terminated prematurely because of lack of efficacy as well as serious side effects [6], whereas clinical testing of BMS-708163 is in progress. Thus, while these examples provide reassurance that well-executed preclinical studies can translate to human patients with regard to pathological targets, they also highlight our limited understanding between causative pathways and clinical decline of cognitive function in $A D$ and our inability to accurately model all aspects of the disease in animals.

Therefore, animal models appear more useful as models of specific disease targets and pathways than of the complete human disease. To optimize their use in that manner, our advisory panel recommended choosing models for preclinical studies that exhibit significant and well-characterized pathology relevant to the disease process of interest (that is, amyloid plaques, tau pathology, neuronal loss, oxidative stress/inflammatory changes, and so on). In addition, models that do not rely solely on mutated human genes to induce pathology are currently underused and can be quite informative. These include aged rodents, pharmacologically and surgically induced models, and other non-transgenic models (Table 1). Since there is no one model for AD, hypothesis testing in multiple models is preferable in order to provide better preclinical validation. In the following sections, we present the panel's recommendations and guidelines for the design, execution, and interpretation of preclinical studies. The objective of this panel was to improve the predictive value of animal models for clinical benefit.

\section{Know your model}

Many transgenic lines show high variability in the extent and time course of expression of disease phenotypes.
Table 2 illustrates common factors affecting phenotype variability, including environmental factors, age, sex, genetic background, litter, transgene copy number, and health status. Not all of these variables can be avoided, but measures can be taken so that phenotype changes due to such factors can be properly noted and potentially corrected [7-9].

\section{Important points to keep in mind}

- Maintain good communication among laboratory members to track deviations from expected phenotypes. Keep careful records to track whether a change in phenotype occurs.

- Identify issues with breeding, such as longer litter intervals, smaller litter sizes, and fewer pregnancies. Identifying such problems early will help keep production on track.

- Screen gene copy numbers and transgene expression level regularly. Document and report.

- Freeze embryos early during characterization of the transgenic line in case phenotypic drift necessitates rederivation of colony.

- Consider your genetic background: Mice may be healthier and more viable on a hybrid background, but genetic drift must be controlled to avoid confounding variables. Keep in mind that certain inbred strains are more prone to characteristics like blindness, hearing loss, and aggression.

- If working with an outside breeder or contract research organization, ask to see historical data on the colony. These data should include rearing conditions such as light cycle, housing type, diet, and health status as well as breeding schemes to assess genetic management of the strain background(s) in the colony.

\section{Improving rigor in study design}

Many animal studies are flawed by methodological weaknesses that compromise study validity and reproducibility. In fact, it was reported that the majority of published effects in amyotrophic lateral sclerosis mice, for example, were likely measurements of noise in the sample population as opposed to actual drug effects [10]. By paying careful attention to study design before starting experiments, investigators can save time and money as well as minimize the probability of false-positive or falsenegative results. Table 3 outlines key study design considerations. In addition, performance on behavioral assays can be highly sensitive to protocol design. For the Morris water maze, for example, variables that can affect performance include water tank size, number and kinds of visual cues, training protocol, how long animals are acclimated to the test room before testing, and strain differences (that can be differentially affected by genetic alterations or the aging process or both). It is important 


\begin{tabular}{l} 
Table 2. Major factors affecting phenotypic variability in \\
mice \\
\hline Environmental \\
Housing system (type of caging/enrichment) \\
Housing density (number of mice per cage) \\
Handler/lnvestigator \\
Light cycle \\
Temperature and humidity \\
Noise and vibration \\
Diet \\
Health status \\
Biological \\
Age \\
Sex \\
Body condition \\
Genetic drift \\
Genetic background (mixed versus inbred) \\
Type of background strain \\
Transgene copy number \\
Transgene expression level
\end{tabular}

to consider and control for these variables in experimental design and use multiple overlapping tests to substantiate behavioral changes.

\section{Develop and employ translatable biomarkers for animal preclinical studies}

Biomarkers have been instrumental in revolutionizing the way we think about human AD and have allowed us to improve clinical trial design and assess target engagement and response to treatments. Animal preclinical studies can also benefit immensely from the use of biomarkers to assess target engagement of investigative treatments, monitor biological responses to treatment in real-time, characterize the translatability of $\mathrm{AD}$ models, and determine the translatability of a novel therapeutic if the same biomarker can be used in a human clinical trial. Although more validation is needed, biomarker methods under development in rodents include imaging - magnetic resonance imaging (MRI), magnetic resonance spectroscopy, functional MRI, arterial spin labeling MRI, flouro-2-deoxy-D-glucose-positron emission tomography (FDG-PET), PET amyloid imaging, PET tau imaging, single-photon emission computed tomography/computed tomography, and others - and biochemical assays on biological fluids such as plasma and cerebrospinal fluid [11-13]. It is important to be aware of the limitations of these biomarkers in rodents, however. For example, functional imaging in mice can be affected by the requirement for either anesthesia or restraint stress. Drawing cerebral spinal fluid from mice is difficult but doable, although it is important to avoid blood contamination [14]. Rat models are becoming more popular and may have advantages in these types of biomarker studies. In any case, whenever possible, biomarker measurements should be incorporated into the study design.

\section{Timing of treatment}

Treatment timing should depend on whether the therapeutic goal is disease prevention, therapeutic intervention (that is, slowing/reversal of established pathology), or symptomatic relief. Tissue should be collected from a proper cohort of animals at the time when treatment is initiated to determine whether the treatment reduced pre-existing pathology in the brain or simply slowed its age-associated accumulation. The degree to which disease stages in mouse models correlate with those in humans is currently unclear. Amyloid mice which do not show tangles or neuronal loss may be representative of presymptomatic or early-stage $\mathrm{AD}$, although this idea is not universally accepted [15]. Where a longitudinal assessment is possible (that is, using peripheral biomarkers, imaging, and certain behavioral responses), taking repeated measures of the same animal can be especially informative and add statistical power. Treatment should be timed on the basis of the optimal stage of pathology development in the animal, which will allow acceptable signal-to-background ratio and dynamic range for experimental treatments. Optimally, demonstration of assay validation should be a prerequisite to embarking on therapeutic studies. Because pathology can vary widely with animal age, control and treatment groups should be age-matched to the greatest extent possible (that is, within days of one another). Pathology and biochemical readouts can also vary widely among animals within a genetically engineered line. The variability in pathology with age and in outcome measures must be assessed in order to power the animal studies properly.

\section{Pharmacokinetics/Pharmacodynamics, ADME-Toxicology}

Studies should include pharmacokinetics (PK) and pharmacodynamics (PD) assessments to determine whether the compound exposure is sufficient and whether it is interacting with the target of interest. Depending on whether a study is exploratory or therapeutic (see 'Exploratory versus therapeutic studies'), the degree to which absorption, distribution, metabolism, excretion, and toxicity (ADMET) are profiled should be considered as part of the prospective study design. In therapeutic studies, it is critical (a) to demonstrate that the test compound has the capacity to reach its target with sufficient concentration and stability to be relevant to prior in vitro studies and (b) to guide the dosing concentrations and frequency to optimize the chance of achieving therapeutic effects. More information about these types of studies can be found in the Alzheimer's Drug Discovery 


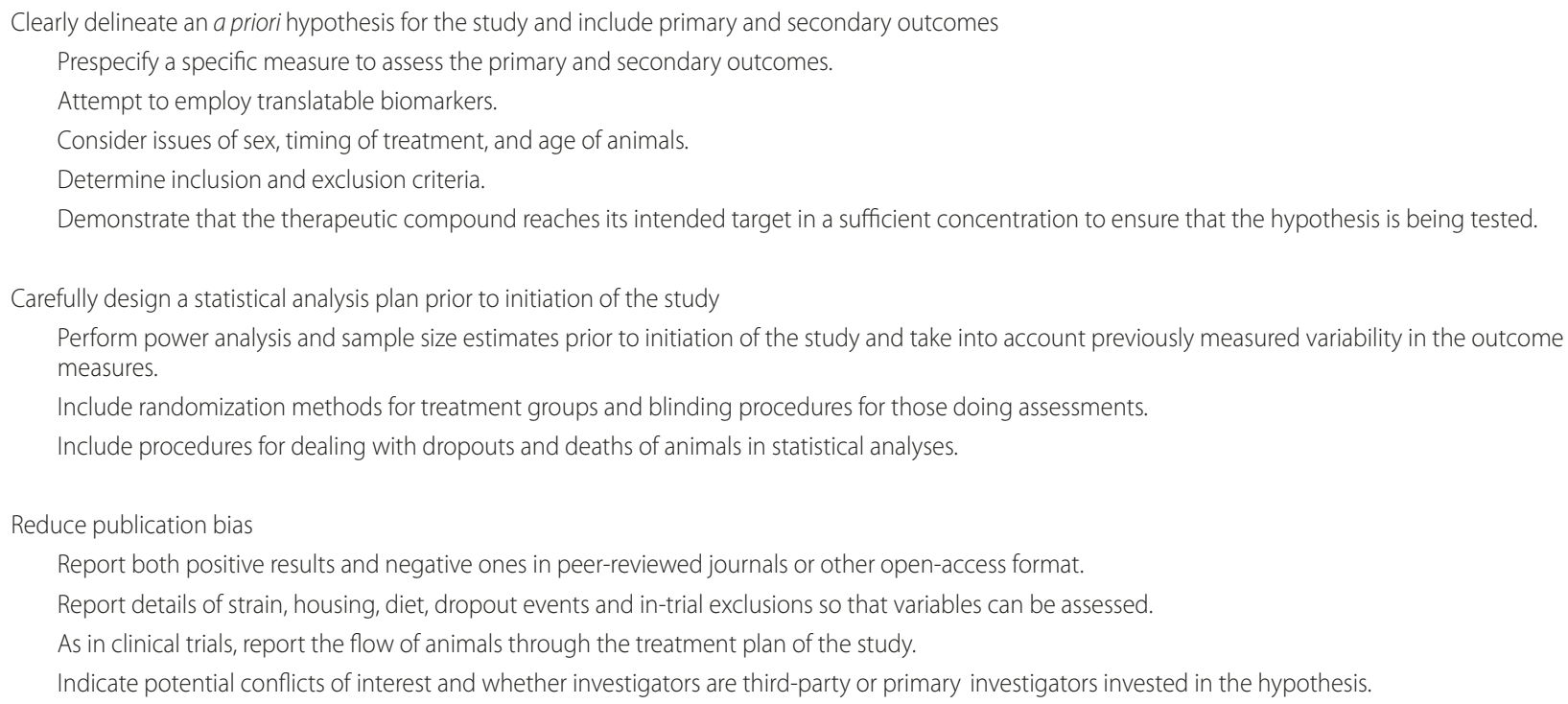

Foundation/Institute for the Study of Aging/Alzheimer's Research Forum Drug Development Tutorial [16]. It is important to note that genetically engineered models may not always be the most cost-effective and translatable models for measuring PK/PD. Wild-type mice are often preferable for use in these studies, but correspondence with genetic background strains in the transgenic studies should be considered.

\section{Statistical analysis plan and methods}

Statistical methods should be chosen before a study is begun, with the anticipated direction of change (onesided or two-sided) in mind. Statistical considerations should be clearly stated in the Methods section of all data reporting. Assessment of endpoint variability in a large sample size is necessary and should be considered in the choice of statistical tests, as the type of variability (normal distribution versus skewed) dictates a parametric versus non-parametric statistical analysis of the data. Guidance or consultation of a statistician should be enlisted in the design of the study once the endpoint variability has been characterized.

\section{Proper quantification}

Both the area and magnitude of pathology should be quantified and reported. Adequate tissue sampling is critical for accurate estimation of pathological burden. For imaging, typically at least six or seven fields per section and six or seven sections per mouse (sampled across multiple affected brain regions) should be measured. The use of unbiased stereology and the optical fractionator method is critical to determining an accurate and statistically reliable neuronal count in brain sections
[17]. Staining and field sampling methods should always be stated in the Methods section, and sampling should be guided by statistical considerations of the variability in the endpoint being interrogated. Analysis and quantification of pathology should be conducted by an individual who is blind to the treatment condition.

\section{Sample size}

Animal studies are frequently underpowered. This was reported to be the single most important factor in influencing spurious research results with animal models [10]. Minimum sample size depends on the expected magnitude of the biological effect, the inherent variability of the target being measured (for example, cerebral spinal fluid $\mathrm{A} \beta$ is much more variable than hippocampal $A \beta)$, variability in behavioral measures or other outcomes, and other factors such as variations in survival within the particular cohort of animals. It is critical to be aware of the natural variability within and among animals in outcome measures in non-treated animals in order to determine the number of animals required for proper statistical powering of therapeutic effects. The sample size needed to achieve significant differences given the variability of disease outcomes in most $\mathrm{AD}$ mouse models has been estimated to be on the order of 20 to 30 per group, rarely achieved in most published mouse studies.

\section{Exclusion criteria}

Animals whose physiological condition appears to be compromised by factors unrelated to the normal progression of the disease should be excluded from the study. A statistical analysis plan should be developed to 
address dropouts and death. Exclusion criteria should be established prior to the study and not on a post hoc basis. Records should be kept of which animals were excluded and why, and such information should be reported explicitly in the Methods section of data reporting.

\section{Balancing and randomization}

Sex-matching and age-matching are critical in study design as both of these factors significantly affect pathological expression. For example, A $\beta$ plaque loads can increase exponentially during the first stages of plaque deposition, and spurious drug effects may be seen in animals analyzed at this stage unless control and treatment groups are age-matched to within days of one another. Mice should be separated into groups by sex, age, and litter and then randomly assigned to either control or treatment groups. In addition, wild-type or young controls or both should be included in study design as a reference point.

\section{Blinding}

Individuals conducting the experiments and those analyzing the results should be blinded to treatment. In the event that a test compound has a readily obvious phenotypic impact on the treated animals, these potentially unblinded observations should be noted by the animal handler but kept segregated to the degree possible from the analyst until the experiment is unblinded. If this is not possible, a full re-design of the experiment may be required. For example, a compound that results in reduced feeding activity (and the phenotypic observation of reduced rate of weight gain) may have an impact on $A \beta$ levels for reasons unrelated to its therapeutic target.

\section{Reporting}

Investigators should report full details of target assay methods and detailed information on the animal model used, including genetic background, copy number, exclusion criteria, and statistical analyses. For behavioral assays, training as well as testing phases should be reported. When possible, scatter-plots should be shown rather than, or in addition to, bar graphs.

Publication bias fueled by a decreased ability or desire to publish negative results represents a huge problem for the field [18]. To increase efficiency, decrease redundant efforts, and learn from others' experiences, it is crucial that negative results be reported. Forums for discussing the quality of negative results, and results that differ from laboratory to laboratory, would aid in the interpretation of negative studies.

\section{Exploratory versus therapeutic studies}

Many investigators, particularly in academic settings, lack the infrastructure and budget to perform the extensive preclinical studies incorporating all of the design, methodological, and statistical considerations recommended here. In addition, comprehensive analyses are not always warranted when the compound or target is being assessed in early stages. As a result, we propose to distinguish between exploratory and therapeutic studies (Table 4).

\section{Exploratory studies}

Exploratory studies should demonstrate that a particular molecular target is involved in a disease process. While exploratory studies do not require the extensive lead optimization, PK/PD, and toxicity analyses undertaken in therapeutic studies, they nonetheless should provide sufficient data to inform the decision of whether to proceed to a therapeutic animal study. Exploratory studies should contain a tolerability/toxicity assay to verify that selected doses are not causing an adverse effect. Multiple doses below the toxicity/tolerability range should be incorporated into an exploratory study, as doses approaching tolerability limits can frequently impact phenotypic outcomes unrelated to the therapeutic target being investigated. Furthermore, terminal blood and brain tissue samples should be collected for possible PK verification later, as the half-life of the test compound may or may not have been consistent with the timing of the putative therapeutic readout.

\section{Therapeutic studies}

Therapeutic studies should be compound-focused and include a full PK/PD and ADMET profile to ensure appropriate dosing and timing of outcomes with respect to exposure of the compound. Toxicity considerations are particularly critical in this context to minimize potential off-target phenotypic impacts on outcome measures. The design, conduct, analysis, and reporting of a therapeutic animal study should be analogous in rigor to those required for human clinical trials.

\section{Future directions}

Below, we list some overall recommendations and challenges that we hope will significantly advance the field by making animal studies more consistent and predictive of future clinical outcomes.

\section{Improve access, characterization, and standardization of} existing Alzheimer's disease mouse and rat models

The field should identify a few models in which key disease phenotypes are well replicated and characterize these models fully with regard to major targets and how they are affected by major biological and experimental variables (for example, age, gender, and housing conditions). Government funding of preclinical animal cores could improve availability and standardization of models. 
Table 4. Exploratory versus therapeutic preclinical studies

\begin{tabular}{|c|c|c|}
\hline Goal & Exploratory studies: mechanism/target-focused & Therapeutic studies: compound-focused \\
\hline \multirow[t]{3}{*}{ Study design } & $\begin{array}{l}\text { Efficacy data should be assessed through multiple outcome } \\
\text { measures. }\end{array}$ & Efficacy results should be demonstrated in more than one model. \\
\hline & \multicolumn{2}{|c|}{ Both exploratory and therapeutic studies should be randomized, placebo-controlled, and blinded, with a dose response. } \\
\hline & \multicolumn{2}{|c|}{ In vivo model considerations for both types of studies include pathogenic stage, age, length of treatment required, and exclusion criteria } \\
\hline ADME & $\begin{array}{l}\text { Studies should include initial physicochemical property } \\
\text { considerations and terminal blood and brain tissue sampling } \\
\text { for assurance of target exposure and possible pharmacokinetics } \\
\text { verification. }\end{array}$ & $\begin{array}{l}\text { Studies should include ADME profiling, full pharmacokinetics/ } \\
\text { pharmacodynamics analysis and distribution/exposure of parent } \\
\text { compound and metabolites. }\end{array}$ \\
\hline Toxicity & $\begin{array}{l}\text { Defined toxicity assessment is not needed, but a simple drug } \\
\text { tolerability assay should be included. }\end{array}$ & $\begin{array}{l}\text { Toxicology should be assessed in the model being studied, with } \\
\text { treatment conducted at levels reliably below adverse event doses. }\end{array}$ \\
\hline Statistics plan & $\begin{array}{l}\text { While statistical considerations need not be as stringent, } \\
\text { prospective power analysis should take into account variability } \\
\text { in the model itself and in outcome measure readouts. }\end{array}$ & $\begin{array}{l}\text { Prospective study design should include sample size power } \\
\text { analyses, statistical evaluation plan, primary and secondary outcome } \\
\text { measures, blinding, and randomization. }\end{array}$ \\
\hline
\end{tabular}

ADME, absorption, distribution, metabolism, and excretion.

In addition, intellectual property creates obstacles to model access. This is a major impediment that needs to be addressed by the scientific and business communities.

Develop more animal models to non-traditional targets and make more use of available non-transgenic models

New animal models that better recapitulate the full complement of human AD pathology and novel nonamyloid targets are needed (Box 1). Aged rodent and non-transgenic models should also be better used as described above.

\section{Standardize commonly used protocols}

To be better able to compare and pool research results, it is important to improve quality control measures across laboratories. Efforts to standardize biomarker protocols have been widely successful [19]. Standardizing protocols for common assays, such as $\mathrm{A} \beta /$ tau extraction, behavioral assays, and measures of neuroprotection and neurodegeneration, in preclinical studies could rapidly advance the interpretation of the testing of novel treatments.

\section{Develop new and higher throughput methods for measuring disease-related outcomes}

Research efforts and funding should be targeted toward better characterizing and developing new methods for targets and outcome measures that are higher throughput for drug discovery. For example, for oxidative stress and inflammation, more emphasis should be placed on the development of pharmacological and metabolic imaging, gene expression, and proteomic screens that provide a broader view of redox and inflammatory changes and allow incorporation of both pro- and anti-oxidant or proand anti-inflammatory species. For behavioral tests, the field would benefit from new translatable behavioral tests that are sensitive to early changes and progression in cognitive function across lifespan and those that lend themselves to repeated testing for optimal within-subject experimental design. Standardization of behavioral methodologies should be attempted to the highest possible degree in order to improve the ability for comparisons of results from multiple laboratories.

\section{Focus on novel targets and outcome measures}

More emphasis should be placed on non-amyloid disease processes and pathways (Box 1), including those related to neuroprotection, synaptic plasticity, oxidative stress, inflammation, vascular targets, mitochondria, and energy use. Assays are available to measure these alternative outcomes.

\section{Standardize review of animal studies in grant applications and scientific publications}

Our advisory panel recommended developing a study design checklist of items for consideration by funding agencies and scientific journals (Table 3). A rating system on study design quality of published papers and a centralized website that lists study results with a forum for comments and feedback would help to improve the selection of compounds for promotion into clinical trials. Furthermore, it would increase the incentive among academic researchers to improve study design.

\section{Establish a public data repository for animal studies}

A public data repository for both positive data and negative data from animal studies would help to improve research efficiency and disseminate negative data. Given that it is often difficult to distinguish a true negative result from a poorly designed study, the critical challenge of such a resource would be quality control. The considerations listed above will be important in providing this sort of distinction and will enable analyses of studies with various strengths and weaknesses in design. Such a repository could help to identify translatable biomarkers 


\section{Box 1. Thinking beyond amyloid: diversifying across disease processes}

While many reasons, including clinical study design, may have contributed to the high-profile clinical trial failures with anti-amyloid treatments to date, the AD field would benefit from diversifying its research portfolio to include non-amyloid disease pathways. Understudied disease processes include neuronal function, vascular changes, oxidative stress and inflammation, mitochondria function, and lipid metabolism. Here, we list methods that can be used to assess some of these processes and that should be more fully exploited.

\section{Neuronal function}

As Alzheimer's disease (AD) progresses, loss of synapses, shrinkage of dendrites, and neuronal death occur. It is these pathological changes that are most closely associated with the cognitive decline seen in the human disease. They can be modeled to some degree in a number of different animal models and are amenable to experimental monitoring as outlined below.

- Measure synaptic density by immunohistochemistry for the synaptic markers, such as synaptophysin. Non-homogeneity of synaptic markers in tissue surrounding plaques can present challenges in analysis. Also, PSD-95, AMPA-R, immediate early genes, and others are better markers for synaptic function than synaptophysin.

- Assess dendritic branching, neuronal structure volume, and total neuron numbers with careful stereology [22].

- Use T2-weighted magnetic resonance imaging (MRI) to indirectly assess neurodegeneration in vivo by measuring structure volumes, and use $1 \mathrm{H}$ magnetic resonance spectroscopy (1H MRS) to quantify N-acetyl-aspartate levels [23].

- Use electrophysiology to measure long-term potentiation in hippocampal slices.

- Employ behavioral studies to assess neuronal function. The Morris water maze, a spatial memory test that can be very sensitive to hippocampal function, is most commonly employed, but alternatives are available that may detect more subtle changes or may be more readily translatable - including attentional set shifting, delayed non-match-to-sample, recognition memory (novel object recognition), discrimination and reversal learning, contextual fear conditioning, and olfaction-based assays - or both [24-26]. Multiple behavioral tests may be needed to fully capture potential therapeutic effects. The use of multiple tests also helps control for factors, such as motivation and overall health, that may influence performance.

\section{Vascular targets}

Vascular pathology in human AD has received little attention, despite increasing evidence that vascular and neuronal dysfunction are closely intertwined and mutually exacerbating in the human disease. For example, cerebral amyloid angiopathy is seen in over $75 \%$ of patients with AD and can lead to vessel rupture, microbleeds, and hemorrhagic stroke [27,28]. Other vascular changes include reduced cerebral blood flow, degeneration of vascular endothelium, basement membrane and smooth muscle, and pathological changes in the neurovascular unit associated with astrocytes, pericytes, and microglia [29]. Attention to vascular targets is further warranted by evidence that amyloid-beta (A $\beta$ ) immunotherapy exacerbates cerebral amyloid angiopathy and microhemorrhages in both mouse AD models and human AD [30]. Experimental methods for monitoring vascular pathology include the following:

- Detect microhemorrhages with Prussian blue and double-stain for vascular Aß. T2-weighted MRI can also be used.

- Assess blood vessel area and patency (quantify using stains, such as tomato lectin, that bind to endothelial cells, together with imaging analysis). Counterstain for components of healthy blood vessels (for example, smooth muscle actin).

- Quantify retinal hemodynamics, which may be translatable as a biomarker in humans [31].

- Measure blood flow directly by arterial spin labeling and dynamic susceptibility contrast MRI and indirectly by FDG-PET or SPECT imaging. Blood volume can be sensitively measured by monocrystalline iron oxide nanoparticle-enhanced MRI.

- Assess the structural integrity of the neurovascular unit by glial fibrillary acetic protein staining and counting total numbers of astrocytic end-feet and the number in contact with blood vessels.

- Assay neurovascular unit function by immunocytochemistry, quantitative polymerase chain reaction, or Western blot measurement of aquaporin 4 or potassium channels (Kir4.1, BK calcium-dependent potassium channel) that are enriched in astrocytic end-feet. It is important to do immunohistochemistry in addition to biochemical measurements as channel distribution can be altered without changes in total levels.

\section{Oxidative stress/Inflammation}

Oxidative stress and inflammation are known to be associated with AD and are relevant targets for drug development, in particular for sporadic AD. However, detecting reliable changes in AD models can be quite difficult.

High oxidative stress is not seen in the most commonly used amyloid precursor protein transgenic (Tg2576) but can be seen in more recent models in which redox pathways have been genetically manipulated [32-34]. These models also show more aspects of AD pathology. Different animal models vary in their upregulation of specific inflammatory profiles; tau models, in particular, show high levels of inflammation in association with neurodegeneration. The time points in which these pathways are assessed is critical since oxidative and inflammatory processes that are toxic at one time point may be protective at others; their levels and effects may also vary among brain regions. 


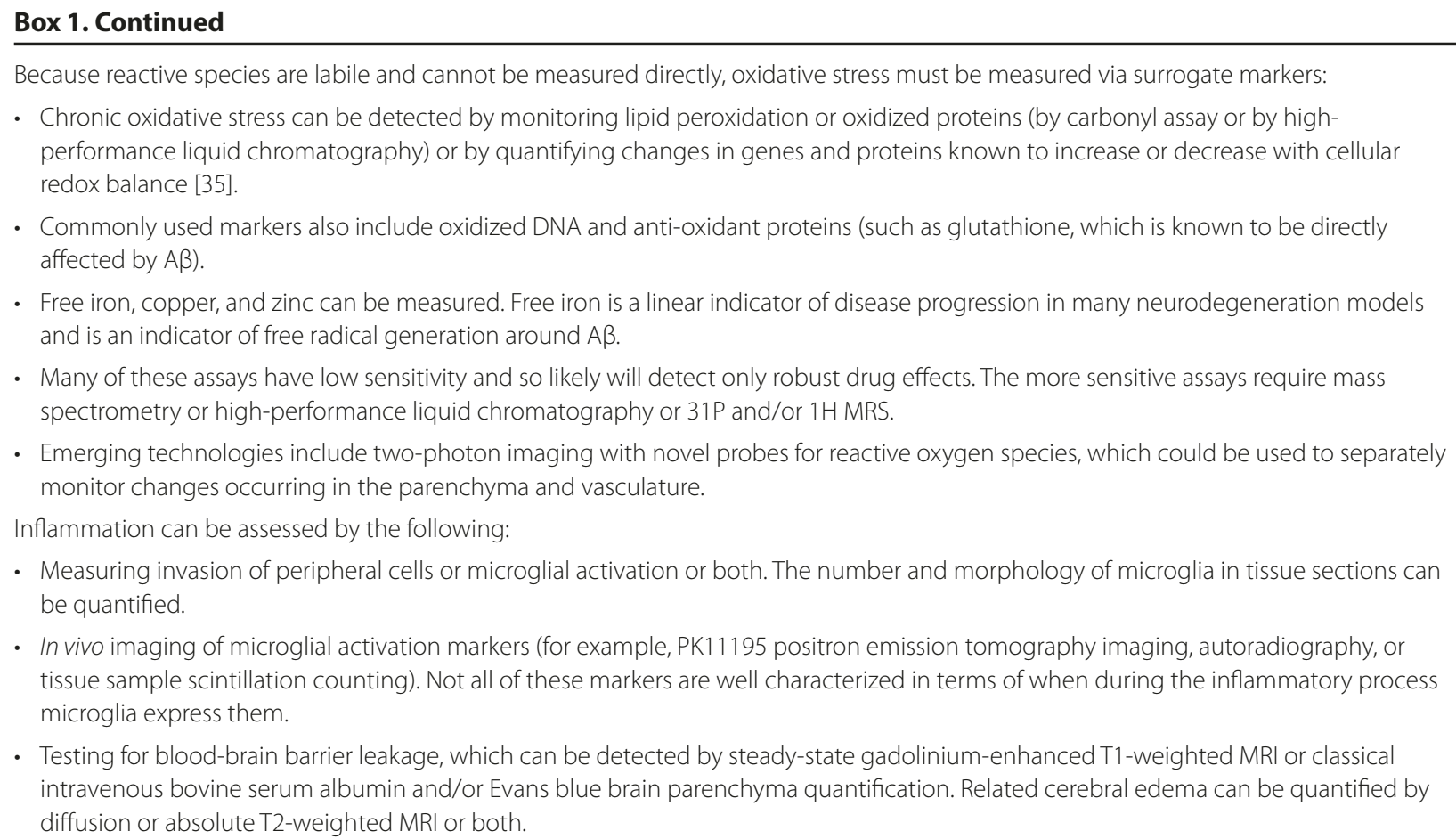

- Testing for blood-brain barrier leakage, which can be detected by steady-state gadolinium-enhanced T1-weighted MRI or classical intravenous bovine serum albumin and/or Evans blue brain parenchyma quantification. Related cerebral edema can be quantified by diffusion or absolute T2-weighted MRI or both.

FDG-PET, fluro-2-deoxy-D positron emission tomography; SPECT, single-photon emission computed tomography.

in animal models that can also be used in human clinical trials to better predict outcomes.

\section{Conclusions}

Our advisory panel produced recommendations in regard to the measurement, analysis, and reporting of relevant targets in $\mathrm{AD}$ animal models. These recommendations stressed the need for quality control measures in breeding and colony maintenance to manage phenotypic variability and outlined key issues related to preclinical animal study design. Distinguishing between exploratory and therapeutic animal studies will aid in defining the scope of the study and the interpretation of results and hopefully will bring some of the rigor of industry preclinical testing to the academic space.

Whereas $A \beta$ likely plays a key role in the development of $\mathrm{AD}$, amyloid deposition alone does not represent the entirety of the disease process or the totality of targets worth investigating for therapeutic intervention. To propel innovation, we should broaden our focus to additional disease-relevant pathways and processes (such as tauopathy, neuroprotection, synaptic plasticity, oxidative stress, inflammation, vascular changes, and mitochondrial dysfunction). Furthermore, non-transgenic models of disease are often underused. Aging is the greatest risk factor for $\mathrm{AD}$; hence, aged rodent models that show cognitive impairment may provide a useful choice for testing investigational therapies targeting mechanisms of neuroprotection, learning, and memory. In addition, models that demonstrate clear neurodegeneration and cell death (such as tau transgenic models and pharmacologically induced models) may be better for testing neuroprotective therapies in general. There is no standard model or set protocol for testing investigational treatments in $\mathrm{AD}$, and it is critical to tailor the choice of model, experimental plan, and outcome measures specifically for the therapy's target or proposed mechanism of action. Animal models of disease will never be able to predict all possible outcomes in humans.

While these recommendations are specifically geared toward AD, they echo many of the sentiments raised in other recent consensus efforts for related diseases such as stroke, vascular cognitive impairment, and amyotrophic lateral sclerosis $[10,20,21]$. These efforts, as a whole, highlight common challenges in animal model selection, study design, interpretation, and reporting which go beyond individual disease states. While each therapeutic area will undoubtedly have its own unique issues, there is much to be learned from shared barriers in translational research. Hopefully, these collective efforts will raise the bar for preclinical studies and will aid in designing animal studies to optimize their interpretability, improve their predictive value, and drive innovation, ultimately improving our efficiency in bringing effective treatments to patients. 


\section{Abbreviations}

$A \beta$, amyloid-beta; $A D$, Alzheimer's disease; $A D M E T$, absorption, distribution, metabolism, excretion, and toxicity; MRI, magnetic resonance imaging PD, pharmacodynamics; PET, positron emission tomography; PK, pharmacokinetics.

\section{Competing interests}

GSB is an employee of and holds shares in Elan Pharmaceuticals, Inc. (South San Francisco, CA, USA), which holds many patents in animal models of AD. $\mathrm{BAH}, \mathrm{IM}, \mathrm{PS}$, and JY are full-time employees of Charles River Laboratories International, Inc. (Wilmington, MA, USA) or its affiliates and may own shares in the company. FL is a full-time employee of Abbott Laboratories (Abbott Park, IL, USA). DRR is a full-time employee of Pfizer Inc (New York, NY, USA). KS-L is a full-time employee of Genentech, Inc. (South San Francisco, CA, USA). CAC has applied for patent protection concerning a mouse model of AD discussed in the manuscript. All other authors declare that they have no competing interests.

\section{Acknowledgments}

We would like to convey our appreciation to key members of the Alzheimer's Drug Discovery Foundation staff for their support in this effort. In particular, we thank Filomena Machleder, Adam Liebling, and Hannah Elkin. We are also grateful to the Charles River CHARTER (Commitment to Humane Animal Research Through Excellence and Responsibility) program for providing funding.

\section{Author details}

'Alzheimer's Drug Discovery Foundation, 57 West 57 Street, Suite 904, New York, NY 10019, USA. Elan Pharmaceuticals, 1000 Gateway Boulevard, South San Francisco, CA 94080, USA. ${ }^{3}$ Evelyn F. and William L. McKnight Brain Institute, University of Florida, 100 S. Newell Drive, Gainesville, FL 32610-0244, USA. ${ }^{4}$ Duke University Medical Center, 201H Bryan Research Building, Research Drive, Durham, NC 27710, USA. 5 University Health Network, Toronto Western Research Institute, 399 Bathurst Street, MP 14-328, Toronto, ON, M5T 2S8, Canada. ${ }^{6}$ Charles River Discovery Services, 3300 Gateway Centre Boulevard, Morrisville, NC 27560, USA. ${ }^{7}$ ALS Therapy Development Institute, 215 First Street, Cambridge, MA 02142, USA. ${ }^{8}$ Leblanc Neuroscience Consulting, 960 Miller Avenue, Berkeley, CA 94708, USA. ${ }^{9}$ Columbia University, 630 West 168th Street, Building PS 12-510, New York, NY 10032, USA. ${ }^{10} \mathrm{Abbott}$ Neuroscience, AP4-2, 100 Abbott Park Road, Abbott Park, IL 60064-6076, USA. "USF Health Byrd Alzheimer Institute, University of South Florida, $4001 \mathrm{E}$. Fletcher Avenue, MDC Box 36, Tampa FL 33613, USA. ${ }^{12}$ Genetically Engineered Models and Services/Charles River Laboratories, Inc., 251 Ballardvale Street, Wilmington, MA 01887, USA. ${ }^{13}$ National Institute on Aging, 7201 Wisconsin Avenue, Gateway Building, Suite 350, Bethesda, MD 20892, USA. ${ }^{14}$ Pfizer Neuroscience Research Unit, MS 8220-3414, Eastern Point Road, Groton, CT 06340, USA. ${ }^{15}$ Genentech, 1 DNA Way, South San Francisco, CA 94080, USA. ${ }^{16}$ Cerebricon Ltd./Charles River Discovery Services, Microkatu 1, Kuopio, Finland 70210 .

Published: 28 September 2011

\section{References}

1. Geerts $\mathrm{H}$ : Of mice and men: bridging the translational disconnect in CNS drug discovery. CNS Drugs 2009, 23:915-926.

2. Nicoll JA, Barton E, Boche D, Neal JW, Ferrer I, Thompson P, Vlachouli C, Wilkinson D, Bayer A, Games D, Seubert P, Schenk D, Holmes C: Abeta species removal after abeta42 immunization. J Neuropathol Exp Neurol 2006, 65:1040-1048.

3. Schenk D, Hagen M, Seubert P: Current progress in beta-amyloid immunotherapy. Curr Opin Immunol 2004, 16:599-606.

4. Henley DB, May PC, Dean RA, Siemers ER: Development of semagacestat (LY450139), a functional gamma-secretase inhibitor, for the treatment of Alzheimer's disease. Expert Opin Pharmacother 2009, 10:1657-1664.

5. Bateman RJ, Siemers ER, Mawuenyega KG, Wen G, Browning KR, Sigurdson WC, Yarasheski KE, Friedrich SW, Demattos RB, May PC, Paul SM, Holtzman DM: A gamma-secretase inhibitor decreases amyloid-beta production in the central nervous system. Ann Neurol 2009, 66:48-54.

6. Lilly halts development of semagacestat for Alzheimer's disease based on preliminary results of phase III clinical trials. PR Newswire 17 Aug. 2010 [http://www.prnewswire.com/news-releases/lilly-halts-development-of- semagacestat-for-alzheimers-disease-based-on-preliminary-results-of-phaseiii-clinical-trials-100874684.html].

7. Pritchett KR, Taft RA: Reproductive biology of the laboratory mouse. In The Mouse in Biomedical Research: Normative Biology, Husbandry, and Models. Volume 3. Edited by Fox JG, Barthold S, Davisson M, Newcomer CE. Burlington, MA, USA: Academic Press; 2007:91-122.

8. Murray KA, Parker NJ: Breeding genetically modified rodents: tips for tracking and troubleshooting reproductive performance. Lab Anim (NY) 2005, 34:36-41.

9. Hampshire V, Davis JA: The role of the veterinary staff in mouse breeding colony management. Lab Anim (NY) 2005, 34:45-49.

10. Scott S, Kranz JE, Cole J, Lincecum JM, Thompson K, Kelly N, Bostrom A, Theodoss J, Al-Nakhala BM, Vieira FG, Ramasubbu J, Heywood JA: Design, power, and interpretation of studies in the standard murine model of ALS. Amyotroph Lateral Scler 2008, 9:4-15.

11. Luo F, Rustay NR, Ebert U, Hradil VP, Cole TB, Llano DA, Mudd SR, Zhang Y, Fox GB, Day M: Characterization of 7- and 19-month-old Tg2576 mice using multimodal in vivo imaging: limitations as a translatable model of Alzheimer's disease. Neurobiol Aging 2010 Oct 18. [Epub ahead of print].

12. Luo F, Rustay NR, Seifert T, Roesner B, Hradil V, Hillen H, Ebert U, Severin JM, Cox BF, Llano DA, Day M, Fox GB: Magnetic resonance imaging detection and time course of cerebral microhemorrhages during passive immunotherapy in living amyloid precursor protein transgenic mice. J Pharmacol Exp Ther 2010, 335:580-588.

13. Portelius E, Zhang B, Gustavsson MK, Brinkmalm G, Westman-Brinkmalm A, Zetterberg H, Lee VM, Trojanowski JQ, Blennow K: Effects of gammasecretase inhibition on the amyloid beta isoform pattern in a mouse model of Alzheimer's disease. Neurodegener Dis 2009, 6:258-262.

14. Liu L, Duff K: A technique for serial collection of cerebrospinal fluid from the cisterna magna in mouse. J Vis Exp 2008, (21) pii:960.

15. Zahs KR, Ashe KH: 'Too much good news' - are Alzheimer mouse models trying to tell us how to prevent, not cure, Alzheimer's disease? Trends Neurosci 2010, 33:381-389.

16. Eckstein J: Drug discovery tutorial [http://www.alzforum.org/drg/tut/tutorial. asp].

17. West MJ, Kawas CH, Stewart WF, Rudow GL, Troncoso JC: Hippocampal neurons in pre-clinical Alzheimer's disease. Neurobiol Aging 2004, 25:1205-1212.

18. Sena ES, van der Worp HB, Bath PM, Howells DW, Macleod MR: Publication bias in reports of animal stroke studies leads to major overstatement of efficacy. PLOS Biol 2010, 8:e1000344.

19. Worldwide Quality Control Set to Tame Biomarker Variation, Alzheimer Research Forum [http://www.alzforum.org/new/detail.asp?id=2287].

20. Hachinski V, ladecola C, Petersen RC, Breteler MM, Nyenhuis DL, Black SE, Powers WJ, DeCarli C, Merino JG, Kalaria RN, Vinters HV, Holtzman DM, Rosenberg GA, Wallin A, Dichgans M, Marler JR, Leblanc GG: National Institute of Neurological Disorders and Stroke-Canadian Stroke Network vascular cognitive impairment harmonization standards. Stroke 2006, 37:2220-2241.

21. Fisher M, Feuerstein G, Howells DW, Hurn PD, Kent TA, Savitz SI, Lo EH; STAIR Group: Update of the stroke therapy academic industry roundtable preclinical recommendations. Stroke 2009, 40:2244-2250.

22. Yang T, Knowles JK, Lu Q, Zhang H, Arancio O, Moore LA, Chang T, Wang Q Andreasson K, Rajadas J, Fuller GG, Xie Y, Massa SM, Longo FM: Small molecule, non-peptide p75 ligands inhibit Abeta-induced neurodegeneration and synaptic impairment. PLoS One 2008, 3:e3604.

23. Moffett JR, Ross B, Arun P, Madhavarao CN, Namboodiri AM: NAcetylaspartate in the CNS: from neurodiagnostics to neurobiology. Prog Neurobiol 2007, 81:89-131.

24. Spinetta MJ, Woodlee MT, Feinberg LM, Stroud C, Schallert K, Cormack LK, Schallert T: Alcohol-induced retrograde memory impairment in rats: prevention by caffeine. Psychopharmacology (Berl) 2008, 201:361-371

25. Montgomery KS, Simmons RK, Edwards G 3rd, Nicolle MM, Gluck MA, Myers CE, Bizon JL: Novel age-dependent learning deficits in a mouse model of Alzheimer's disease: implications for translational research. Neurobio/ Aging 2011, 32:1273-1285.

26. Clark RE, Martin SJ: Interrogating rodents regarding their object and spatial memory. Curr Opin Neurobiol 2005, 15:593-598.

27. Kalaria RN, Ballard C: Overlap between pathology of Alzheimer disease and vascular dementia. Alzheimer Dis Assoc Disord 1999, 13 Suppl 3:S115-S123.

28. Zlokovic BV: New therapeutic targets in the neurovascular pathway in 
Alzheimer's disease. Neurotherapeutics 2008, 5:409-414.

29. Wilcock DM, Vitek MP, Colton CA: Vascular amyloid alters astrocytic water and potassium channels in mouse models and humans with Alzheimer's disease. Neuroscience 2009, 159:1055-1069.

30. Wilcock DM, Colton CA: Immunotherapy, vascular pathology, and microhemorrhages in transgenic mice. CNS Neurol Disord Drug Targets 2009, 8:50-64.

31. Guo L, Duggan J, Cordeiro MF: Alzheimer's disease and retinal neurodegeneration. Curr Alzheimer Res 2010, 7:3-14

32. Colton CA, Vitek MP, Wink DA, Xu Q, Cantillana V, Previti ML, Van Nostrand WE, Weinberg JB, Dawson H: NO synthase 2 (NOS2) deletion promotes multiple pathologies in a mouse model of Alzheimer's disease. Proc Natl Acad Sci USA 2006, 103:12867-12872.

33. Colton CA, Wilcock DM, Wink DA, Davis J, Van Nostrand WE, Vitek MP: The effects of NOS2 gene deletion on mice expressing mutated human AbetaPP. J Alzheimers Dis 2008, 15:571-587.

34. Wilcock DM, Lewis MR, Van Nostrand WE, Davis J, Previti ML, Gharkholonarehe N, Vitek MP, Colton CA: Progression of amyloid pathology to Alzheimer's disease pathology in an amyloid precursor protein transgenic mouse model by removal of nitric oxide synthase 2. J Neurosci 2008, 28:1537-1545.

35. Sultana R, Butterfield DA: Identification of the oxidative stress proteome in the brain. Free Radic Biol Med 2011, 50:487-494.

36. Hsiao K, Chapman P, Nilsen S, Eckman C, Harigaya Y, Younkin S, Yang F, Cole G: Correlative memory deficits, Abeta elevation, and amyloid plaques in transgenic mice. Science 1996, 274:99-102

37. Games D, Adams D, Alessandrini R, Barbour R, Berthelette P, Blackwell C, Carr T, Clemens J, Donaldson T, Gillespie F, Guido T, Hagopian S, Johnson-Wood K, Khan K, Lee M, Leibowitz P, Lieberburg I, Little S, Masliah E, Mcconlogue L, Montoya-Zavala M, Mucke L, Paganini L, Penniman E, Power M, Schenk D, Seubert P, Snyder B, Soriano F, Tan H, et al:: Alzheimer-type neuropathology in transgenic mice overexpressing V717F beta-amyloid precursor protein. Nature 1995, 373:523-527.

38. Moechars D, Dewachter I, Lorent $K$, Reversé D, Baekelandt V, Naidu A, Tesseur I, Spittaels K, Haute CV, Checler F, Godaux E, Cordell B, Van Leuven F: Early phenotypic changes in transgenic mice that overexpress different mutants of amyloid precursor protein in brain. J Biol Chem 1999, 274:6483-6492.

39. Rönnbäck A, Zhu S, Dillner K, Aoki M, Lilius L, Näslund J, Winblad B, Graff C: Progressive neuropathology and cognitive decline in a single Arctic APP transgenic mouse model. Neurobio/ Aging 2011, 32:280-292.

40. Herzig MC, Winkler DT, Burgermeister P, Pfeifer M, Kohler E, Schmidt SD, Danner S, Abramowski D, Stürchler-Pierrat C, Bürki K, van Duinen SG, MaatSchieman ML, Staufenbiel M, Mathews PM, Jucker M: Abeta is targeted to the vasculature in a mouse model of hereditary cerebral hemorrhage with amyloidosis. Nat Neurosci 2004, 7:954-960.

41. Lord A, Kalimo H, Eckman C, Zhang XQ, Lannfelt L, Nilsson LN: The Arctic Alzheimer mutation facilitates early intraneuronal Abeta aggregation and senile plaque formation in transgenic mice. Neurobiol Aging 2006, 27:67-77.

42. Davis J, Xu F, Deane R, Romanov G, Previti ML, Zeigler K, Zlokovic BV, Van Nostrand WE: Early-onset and robust cerebral microvascular accumulation of amyloid beta-protein in transgenic mice expressing low levels of a vasculotropic Dutch/lowa mutant form of amyloid beta-protein precursor. J Biol Chem 2004, 279:20296-20306.

43. Cheng IH, Palop JJ, Esposito LA, Bien-Ly N, Yan F, Mucke L: Aggressive amyloidosis in mice expressing human amyloid peptides with the Arctic mutation. Nat Med 2004, 10:1190-1192.

44. Chishti MA, Yang DS, Janus C, Phinney AL, Horne P, Pearson J, Strome R, Zuker N, Loukides J, French J, Turner S, Lozza G, Grilli M, Kunicki S, Morissette C, Paquette J, Gervais F, Bergeron C, Fraser PE, Carlson GA, George-Hyslop PS, Westaway D: Early-onset amyloid deposition and cognitive deficits in transgenic mice expressing a double mutant form of amyloid precursor protein 695. J Biol Chem 2001, 276:21562-21570.

45. Mucke L, Masliah E, Yu GQ, Mallory M, Rockenstein EM, Tatsuno G, Hu K, Kholodenko D, Johnson-Wood K, McConlogue L: High-level neuronal expression of abeta 1-42 in wild-type human amyloid protein precursor transgenic mice: synaptotoxicity without plaque formation. J Neurosci 2000, 20:4050-4058

46. Ramsden M, Kotilinek L, Forster C, Paulson J, McGowan E, SantaCruz K, Guimaraes A, Yue M, Lewis J, Carlson G, Hutton M, Ashe KH: Age-dependent neurofibrillary tangle formation, neuron loss, and memory impairment in a mouse model of human tauopathy (P301L). J Neurosci 2005.
25:10637-10647

47. Lim F, Hernandez F, Lucas JJ, Gomez-Ramos P, Moran MA, Avila J: FTDP-17 mutations in tau transgenic mice provoke lysosomal abnormalities and Tau filaments in forebrain. Mol Cell Neurosci 2001, 18:702-714.

48. Terwel D, Lasrado R, Snauwaert J, Vandeweert E, Van Haesendonck C, Borghgraef P, Van Leuven F: Changed conformation of mutant Tau-P301L underlies the moribund tauopathy, absent in progressive, nonlethal axonopathy of Tau-4R/2N transgenic mice. J Biol Chem 2005, 280:3963-3973.

49. Zhang B, Higuchi M, Yoshiyama Y, Ishihara T, Forman MS, Martinez D, Joyce S, Trojanowski JQ, Lee VM: Retarded axonal transport of R406W mutant tau in transgenic mice with a neurodegenerative tauopathy. J Neurosci 2004, 24:4657-4667.

50. Holcomb L, Gordon MN, McGowan E, Yu X, Benkovic S, Jantzen P, Wright K, Saad I, Mueller R, Morgan D, Sanders S, Zehr C, O'Campo K, Hardy J, Prada CM, Eckman C, Younkin S, Hsiao K, Duff K: Accelerated Alzheimer-type phenotype in transgenic mice carrying both mutant amyloid precursor protein and presenilin 1 transgenes. Nat Med 1998, 4:97-100.

51. Borchelt DR, Ratovitski T, van Lare J, Lee MK, Gonzales V, Jenkins NA, Copeland NG, Price DL, Sisodia SS: Accelerated amyloid deposition in the brains of transgenic mice coexpressing mutant presenilin 1 and amyloid precursor proteins. Neuron 1997, 19:939-945.

52. Siman R, Reaume AG, Savage MJ, Trusko S, Lin YG, Scott RW, Flood DG Presenilin-1 P264L knock-in mutation: differential effects on abeta production, amyloid deposition, and neuronal vulnerability. J Neurosci 2000, 20:8717-8726.

53. Lewis J, Dickson DW, Lin WL, Chisholm L, Corral A, Jones G, Yen SH, Sahara N, Skipper L, Yager D, Eckman C, Hardy J, Hutton M, McGowan E: Enhanced neurofibrillary degeneration in transgenic mice expressing mutant tau and APP. Science 2001, 293:1487-1491.

54 Ribé EM, Pérez M, Puig B, Gich I, Lim F, Cuadrado M, Sesma T Catena S, Sánchez B, Nieto M, Gómez-Ramos P, Morán MA, Cabodevilla F, Samaranch L, Ortiz L, Pérez A, Ferrer I, Avila J, Gómez-Isla T: Accelerated amyloid deposition, neurofibrillary degeneration and neuronal loss in double mutant APP/tau transgenic mice. Neurobiol Dis 2005, 20:814-822.

55. Pérez M, Ribe E, Rubio A, Lim F, Morán MA, Ramos PG, Ferrer I, Isla MT, Avila J: Characterization of a double (amyloid precursor protein-tau) transgenic: tau phosphorylation and aggregation. Neuroscience 2005, 130:339-347.

56. Oddo S, Caccamo A, Shepherd JD, Murphy MP, Golde TE, Kayed R, Metherate R, Mattson MP, Akbari Y, LaFerla FM: Triple-transgenic model of Alzheimer's disease with plaques and tangles: intracellular Abeta and synaptic dysfunction. Neuron 2003, 39:409-421.

57. Russell MJ, Bobik M, White RG, Hou Y, Benjamin SA, Geddes JW: Age-specific onset of beta-amyloid in beagle brains. Neurobiol Aging 1996, 17:269-273.

58. Gallagher M, Nicolle MM: Animal models of normal aging: relationship between cognitive decline and markers in hippocampal circuitry. Behav Brain Res 1993, 57:155-162.

59. Gower AJ, Lamberty Y: The aged mouse as a model of cognitive decline with special emphasis on studies in NMRI mice. Behav Brain Res 1993, 57:163-173.

60. Price DL, Martin $\sqcup$, Sisodia SS, Wagster MV Koo EH, Walker LC, Koliatsos VE, Cork LC: Aged non-human primates: an animal model of age-associated neurodegenerative disease. Brain Pathol 1991, 1:287-296.

61. Okuma Y, Nomura Y: Senescence-accelerated mouse (SAM) as an animal model of senile dementia: pharmacological, neurochemical and molecular biological approach. Jpn J Pharmacol 1998, 78:399-404.

62. Tomobe K, Nomura Y: Neurochemistry, neuropathology, and heredity in SAMP8: a mouse model of senescence. Neurochem Res 2009, 34:660-669.

63. Butterfield DA, Poon HF: The senescence-accelerated prone mouse (SAMP8): a model of age-related cognitive decline with relevance to alterations of the gene expression and protein abnormalities in Alzheimer's disease. Exp Gerontol 2005, 40:774-783.

64. Yamada M, Chiba T, Sasabe J, Nawa M, Tajima H, Niikura T, Terashita K, Aiso S, Kita Y, Matsuoka M, Nishimoto I: Implanted cannula-mediated repetitive administration of Abeta25-35 into the mouse cerebral ventricle effectively impairs spatial working memory. Behav Brain Res 2005, 164:139-146.

65. Freir DB, Holscher C, Herron CE: Blockade of long-term potentiation by beta-amyloid peptides in the CA1 region of the rat hippocampus in vivo. J Neurophysiol 2001, 85:708-713.

66. Cada A, de la Torre JC, Gonzalez-Lima F: Chronic cerebrovascular ischemia in aged rats: effects on brain metabolic capacity and behavior. Neurobiol 
Aging 2000, 21:225-233.

67. Schmidt N, Ferger B: Neurochemical findings in the MPTP model of Parkinson's disease. J Neural Transm 2001, 108:1263-1282.

68. Stoehr JD, Mobley SL, Roice D, Brooks R, Baker LM, Wiley RG, Wenk GL: The effects of selective cholinergic basal forebrain lesions and aging upon expectancy in the rat. Neurobiol Learn Mem 1997, 67:214-227.

69. Research models, Alzheimer Research Forum [http://www.alzforum.org/ $\mathrm{res} / \mathrm{com} / \mathrm{tra} /$ default.asp]. doi:10.1186/alzrt90

Cite this article as: Shineman DW, et al:: Accelerating drug discovery for

Alzheimer's disease: best practices for preclinical animal studies. Alzheimer's

Research \& Therapy 2011, 3:28. 